\title{
Thermospheric inter-annual variability and its potential connection to ENSO and stratospheric QBO
}

\author{
Huixin Liu*
}

\begin{abstract}
Using a 46-year-long dataset of the thermospheric density during 1967-2012, we examined the inter-annual variability in the thermosphere at $400 \mathrm{~km}$ and its potential connection to El-Nino Southern Oscillation (ENSO) and stratospheric Quasi-Biennial Oscillation (QBO). Wavelet analysis reveals two major modes of the thermosphere inter-annual oscillation, with the slower mode having an average period of $\sim 64$ months and the faster mode of $\sim 28$ months. The slower mode bears high coherence with the ENSO during 1982-2012, while the faster mode is found to vary coherently with the QBO around 1972, 1982 and 2002. Further examination reveals that the coherence between QBO and the faster mode is significantly influenced by their common coherent variation with the solar flux, while high coherence between the slower mode and ENSO is much less contaminated. Therefore, we conclude that the 28-month periodicity in thermospheric density may be caused by both QBO and solar radiation, whereas the 64-month periodicity possibly arises mainly from ENSO processes, with little/small contribution from solar radiation.
\end{abstract}

\section{Introduction}

The thermosphere is the upper part of the Earth's atmosphere, occupying the region between about $100-600 \mathrm{~km}$ altitude. This region is not only important for satellite operations because of air drag, but also scientifically important for vertical coupling between the upper and lower atmosphere because of its high sensitivity to both solar forcing and lower atmosphere forcing. The thermosphere is known to respond closely to solar forcing at various timescales ranging from the solar cycle to a few minutes during solar flares (e.g., Liu et al. 2005, 2007). In recent years, the thermosphere has also been found to be sensitive to meteorological forcing from the lower atmosphere. For instance, it responds to the non-migrating tidal forcing due to the land-sea distribution and forms a wave-4 structure in the zonal distribution of neutral density and wind (Liu et al. 2009; Häusler et al. 2007). It also responds globally to stratosphere sudden warming (SSW) events with semi-diurnal perturbations in the

\footnotetext{
*Correspondence: huixin@serc.kyushu-u.ac.jp Department of Earth and Planetary Science, Kyushu University, Fukuoka, Japan
}

thermosphere temperature and a zonal mean cooling (Liu et al. 2011, 2014). Furthermore, the thermosphere shows a long-term cooling trend, in response to the increase of $\mathrm{CO}_{2}$ in the atmosphere during the twentiethcentury global warming (Emmert et al. 2010). The agents which teleconnect the lower and upper atmosphere in these cases are atmospheric tides for the former two and $\mathrm{CO}_{2}$ infrared radiative cooling for the latter.

In the lower atmosphere, there are two distinct phenomena which occur periodically. One is the El-Nino Southern Oscillation (ENSO), and the other is the QuasiBiennial Oscillation (QBO). ENSO refers to periodic variations in the sea surface temperatures over the tropical eastern Pacific Ocean. It has two phases, with the warming phase called El-Nino and cooling phase called LaNina. ENSO occurs on average every $\sim 5$ years, but varies considerably between 2-7 years (see, e.g., Wang and Picaut 2004). QBO refers to the quasi-periodic oscillation of the equatorial zonal wind in the tropical stratosphere with a mean period of about 28 months, ranging between 20 and 36 months (see, e.g., Baldwin 2001).

There have been reports on the effects of these oscillating meteorological phenomena on the ionosphere. For 
instance, ionospheric foF2 at two stations was found to highly correlate with ENSO (Pedatella and Forbes 2009). The equatorial electrojet and ionospheric foF2, hmF2 were found to oscillate at periods around 26-27 months, which was attributed to the influence of the stratospheric QBO (Olsen 1994; Kane 1995). Since the thermosphere is closely coupled to the ionosphere, it is interesting to examine whether the thermosphere bears imprints of ENSO and QBO as well. This study explores such a possibility by using a long time series of thermosphere density observations.

\section{Data}

Since ENSO occurs only once every couple of years, we need a sufficiently long dataset to be able to examine possible ENSO signatures in the thermosphere. For this purpose, the thermospheric density dataset first introduced by Emmert (2009) and later extended to 2012 is employed. This dataset provides daily globally averaged thermospheric density obtained from orbital decay measurements of about 5000 satellites during the period of 1967-2012. Note that the temporal resolution of the data is 3-6 days, due to a 3- to 6-day smoothing procedure in the density retrieval (Emmert 2009). Density values are given at three different heights of 250, 400 and $550 \mathrm{~km}$. For our analysis, we calculate monthly averaged values using only data under quiet geomagnetic conditions (daily average $\mathrm{Kp}<2^{+}$).

To examine the thermosphere density perturbation possibly related to ENSO and QBO, we take density residuals by subtracting the NRLMSISE-00 model values from the measurements. By doing so, we remove density variations due to local time, season, solar cycle, and geomagnetic activity effects. Figure 1a shows the observed and model values. They are very close to each other, demonstrating NRLMSISE-00's ability in capturing most solar and seasonal driven variabilities in the globally averaged thermospheric density. The residual $(\Delta \rho)$ at $400 \mathrm{~km}$ is shown in Fig. 1b. To focus on inter-annual oscillations, a 12-month running mean is applied before subsequent analysis (thick curve in Fig. 1b). Although the model does not take into account lower atmosphere forcing like $\mathrm{CO}_{2}$ or stratospheric sudden warmings, it is not a big problem for our analysis here as their effects hardly enter the timescales we are interested in this study, which is between about $2-7$ years.

ENSO is represented by the commonly used Nino3 index provided by the Japanese Meteorological Agency (http://www.data.jma.go.jp/gmd/cpd/db/elnino/index/ dattab.html). This index is calculated from the sea surface temperature anomaly in eastern Pacific region of $5^{\circ} \mathrm{N}-5^{\circ}$ $\mathrm{S}, 90^{\circ} \mathrm{W}-150^{\circ} \mathrm{W}$. Stratospheric $\mathrm{QBO}$ is represented by the zonal wind at 30 -hPa pressure level provided by the Frei
University Berlin (http://www.geo.fu-berlin.de/en/met/ $\mathrm{ag} /$ strat/produkte/qbo/). Both Nino3 and QBO indices come as monthly values (Fig. 1c, d). Similar to the thermospheric density residual, we apply a 12 -month running mean to suppress fluctuations below one year.

The solar flux is also used, particularly in the later part of the study. The proxy $P 10.7=(f 10.7+f 10.7 A) / 2$ is chosen to represent the solar flux, since it is shown to be more suitable than f10.7 as a linear indicator for the solar EUV radiation (e.g., Richards et al. 1994; Liu et al. 2006). Here f10.7A is the centered 81-day average of the f10.7 values. Monthly averaged values are used to be consistent with the temporal resolution of ENSO and QBO indices.

\section{Results and discussion}

The data series of density residual, Nino3, and QBO obtained above are subjected to various spectrum analyses to reveal the characteristics of their inter-annual oscillations. Since results at $250 \mathrm{~km}$ are rather similar to that at $400 \mathrm{~km}$, we present the results at $400 \mathrm{~km}$ altitude to avoid repetition. Results at $550 \mathrm{~km}$ are discussed afterward.

We first apply simple Fourier spectrum analysis using the Lomb-Scargle method (Lomb 1976; Scargle 1982) to bring out the overall (in contrast to wavelet) periodicities in these datasets. Periodograms in Fig. 2 show that the density residual at $400 \mathrm{~km}$ bears a distinct peak around 62 months and two broad peaks at $\sim 78$ and $\sim 105$ months (Fig. 2a). Nino3 exhibits two isolated peaks around 43 and 62 months (Fig. 2b), while the QBO shows a prominent peak at $\sim 28$ months (Fig. 2c). These periodicities in the Nino3 and QBO are consistent with known values. The P10.7 index shows no significant peak below 100 months.

Since Fourier analysis yields only a time mean spectrum of a data series, we perform wavelet analysis to reveal more accurate information on the periodicities and their temporal evolution. As illustrated in Fig. 3a, the density residual experiences oscillations in several periodicity bands. The band of low periodicity is centered around 28 months with a range of 20-36 months. These oscillations likely produced the two minor peaks between 20 and 40 months in the mean spectrum shown in Fig. 2a. Because these oscillations occur only intermittently around 1972, 1982, 1992 and 2002, when averaged over the entire period, the spectral peak drops below the $95 \%$ significance level as seen in Fig. 2a. On the other hand, these intermittent occurrences indicate that this oscillation is likely regulated by solar cycle. This point is further confirmed later. Two higher periodicities centered around 52 and 88 months occur during 1975-1990 and converge to one centered around $\sim 64$ months after 1990. Meanwhile, Nino3 exhibits a broad peak around 

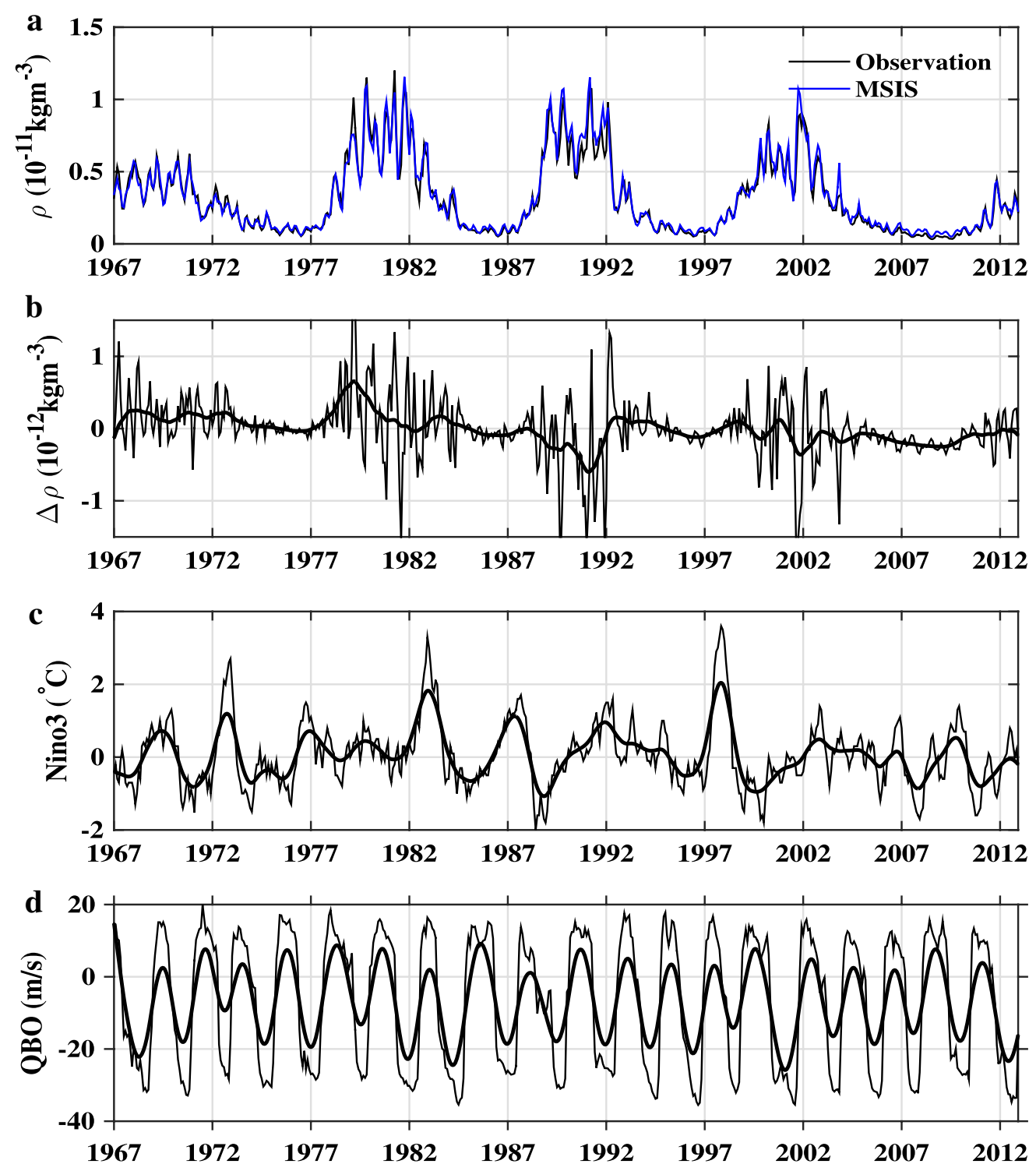

Fig. 1 Time series during 1967-2012. a The observed (black line) and NRLMSISE-00 modeled (green line) values of the global mean thermospheric density at $400 \mathrm{~km}$ altitude. b The density residual (thin line) and its yearly running mean (thick line). c Nino3 index and its yearly running mean. $\mathbf{d}$ $\mathrm{QBO}$ and its yearly running mean

42 months before 1972 (Fig. 3b). It bifurcated to two separate peaks after 1972, with one remaining around 42 months and another one shifting from $\sim 52$ months around 1987 to $\sim 64$ months during 1997-2010. The QBO exhibits the known periodicity around 28 months, with a range of $24-36$ months (Fig. 3c). The solar flux index P10.7 shows only one peak with greater than $95 \%$ significance, which is around 128 months, roughly corresponding to the solar cycle.

To further examine how coherently these oscillations vary with each other, wavelet coherence analysis is carried out. The result shown in Fig. 4 (top panel) reveals a high coherence over 0.9 between Nino3 and the density residual at the periodicity centered around 64 months with a range of 56-78 months. The phase shift is indicated by the arrows, being persistently around $\sim 60^{\circ}$. This means that ENSO leads the density oscillation by $\sim 60^{\circ}$, which corresponds to about 10 months for a periodicity of 64 months. Note that the Nino3 index represents variations in the sea surface temperature, and it takes about 5 months for these changes in the ocean to transfer to the tropical troposphere (Trenberth et al. 2002). The bottom 

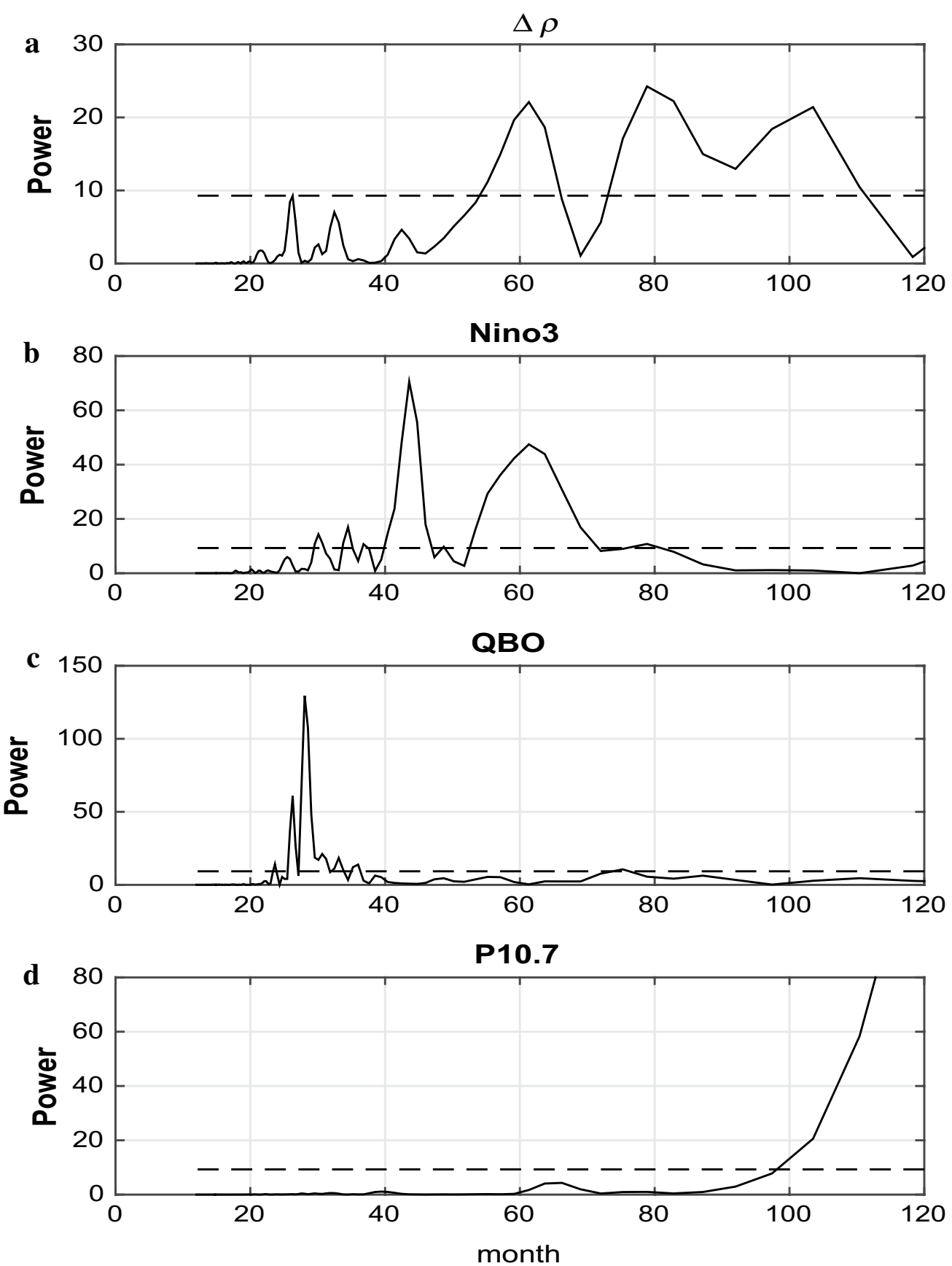

Fig. 2 The Lomb-Scargle periodogram of a the density residual at $400 \mathrm{~km}$ altitude; b Nino3 index; c QBO index; $\mathbf{d}$ P10.7 index. Dash lines indicate $95 \%$ significance level

panel of Fig. 4 reveals high coherence between the density and QBO around 1972, 1982 and 2002.

The high coherences obtained above are very encouraging. However, a concern arises as to how much these coherences are attributed simply to their common covariation with the solar flux. For instance, the 64-month periodicity where the density has high coherence with ENSO is very close to the second harmonic of the 11-year solar cycle. To clarify whether there is any contamination due to this aspect, we carried out coherence analysis separately between the density residual and solar flux and between Nino3 index and the solar flux. Results in 

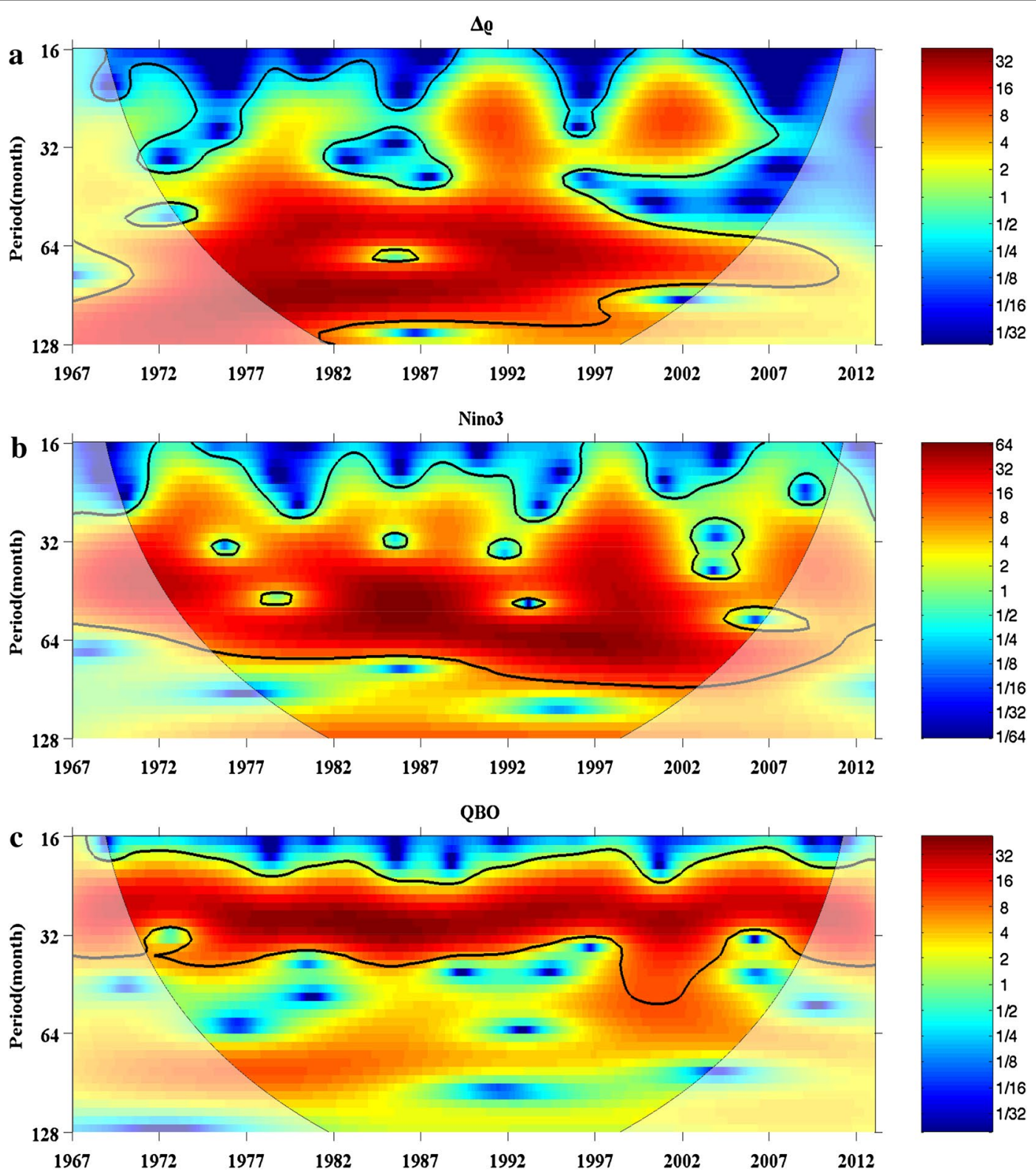

P10.7

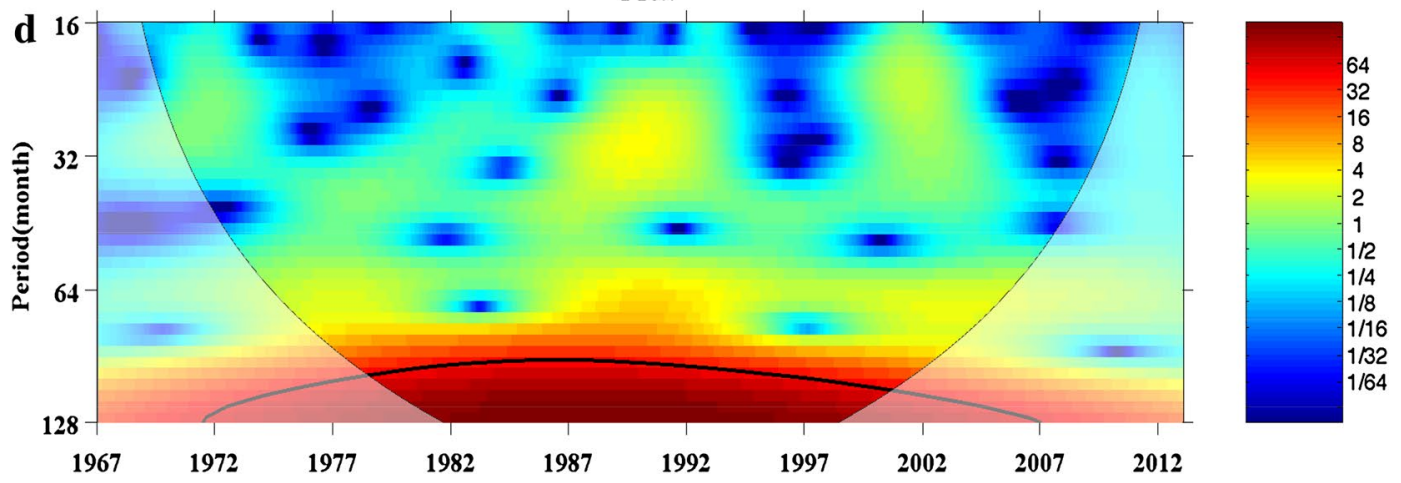

Fig. 3 The wavelet power spectrum of $\mathbf{a}$ the density residual at $400 \mathrm{~km}$ altitude; $\mathbf{b}$ Nino3 index; c QBO index; d P10.7 during 1967-2012. The thick contour encloses regions of greater than $95 \%$ significance level 


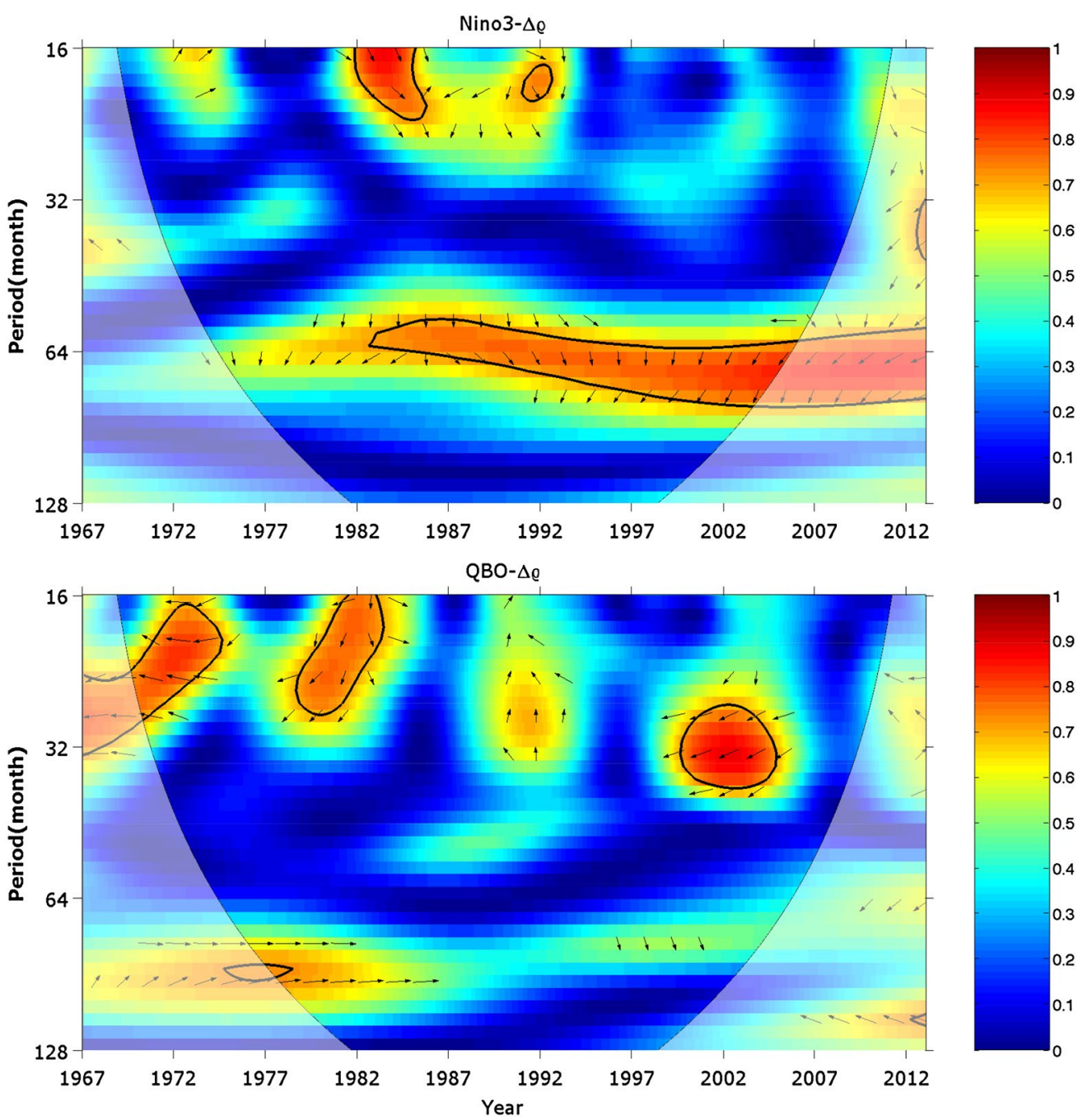

Fig. 4 The wavelet coherence between the density residual at $400 \mathrm{~km}$ altitude and Nino3 index (upper) and between the density residual and QBO index (bottom). Thick contours enclose regions of greater than $95 \%$ significance level. The arrows indicate the relative phase relationship between the time series, right in-phase; left anti-phase; down Nino3/QBO leading $\Delta \rho$ by $90^{\circ}$; up $\Delta \rho$ leading Nino3/QBO by $90^{\circ}$

Fig. 5 reveal a coherence between the density and P10.7 around 64 months (top panel), but being mostly insignificant except for during periods before 1976 and around 1997. On the other hand, Nino3 index shows no significant coherence with P10.7 at periods between 50 and 80 months (middle panel). Therefore, these examinations indicate that the strong coherence between the density and Nino3 index is likely a true signature of the lowerupper atmosphere coupling during ENSO periods.

Similarly, we have examined possible solar contamination to the high $\Delta \rho-\mathrm{QBO}$ coherence around 28 months. As seen in Fig. 5 (upper panel), the density residual shows high coherence with P10.7 at periods of 16-32 months around 1972 and during most time of 1987-2012. At the same time, the QBO shows high coherence with P10.7 between 17 and 32 months around 1972, 1982, 1992, 2002 and 2012. Thus, it is difficult to tell whether the high coherence between the QBO and density residual (lower panel in Fig. 4) is a true coupling signature between the two or simply caused by their common coherence with the solar flux. In other words, we may say that the 28-month periodicity of the thermospheric density could be caused by both QBO and solar radiation.

Here we note that the QBO index is obtained from the wind velocities at the $30-\mathrm{hPa}$ pressure level. Using winds at other pressure levels in the stratosphere will not significantly impact the coherence pattern shown in the lower panel of Fig. 4, except for producing a somewhat different phase shift (that is, the arrow direction may change). This is because the extension of the QBO-wind fields 

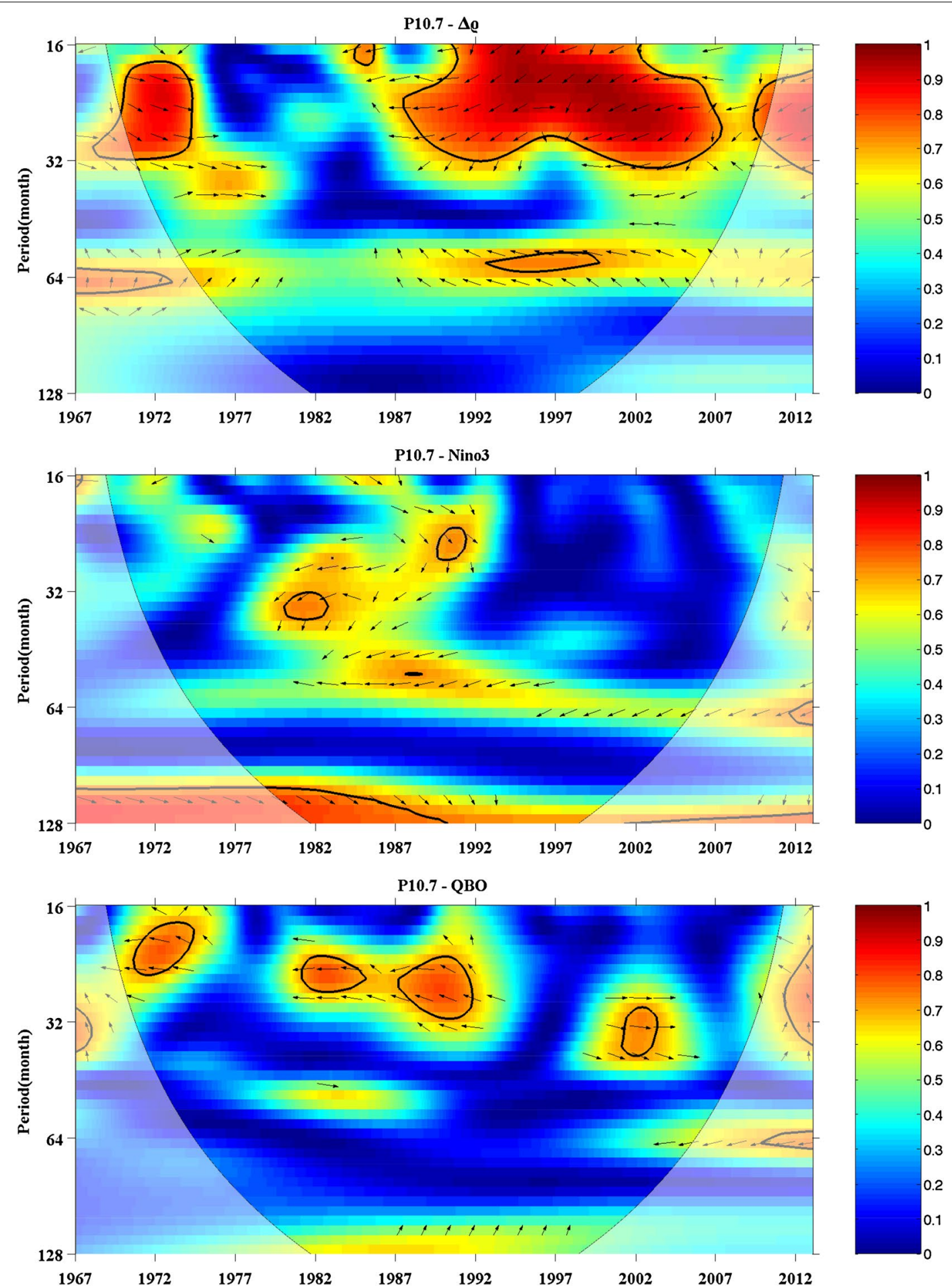

Fig. 5 The wavelet coherence between P10.7 index and the density residual at $400 \mathrm{~km}$ altitude (upper), between the P10.7 and Nino3 (middle), between the P10.7 and QBO. The thick contour encloses regions of greater than $95 \%$ significance level

throughout the vertical domain of the stratosphere is not random, but rather organized with a continuous downward phase shift (Baldwin 2001).
Finally, we discuss the density variation at $550 \mathrm{~km}$ altitudes. Examination of Fig. $6 \mathrm{~b}$ tells us that it has almost no coherence with the Nino3 index, indicating weakening 

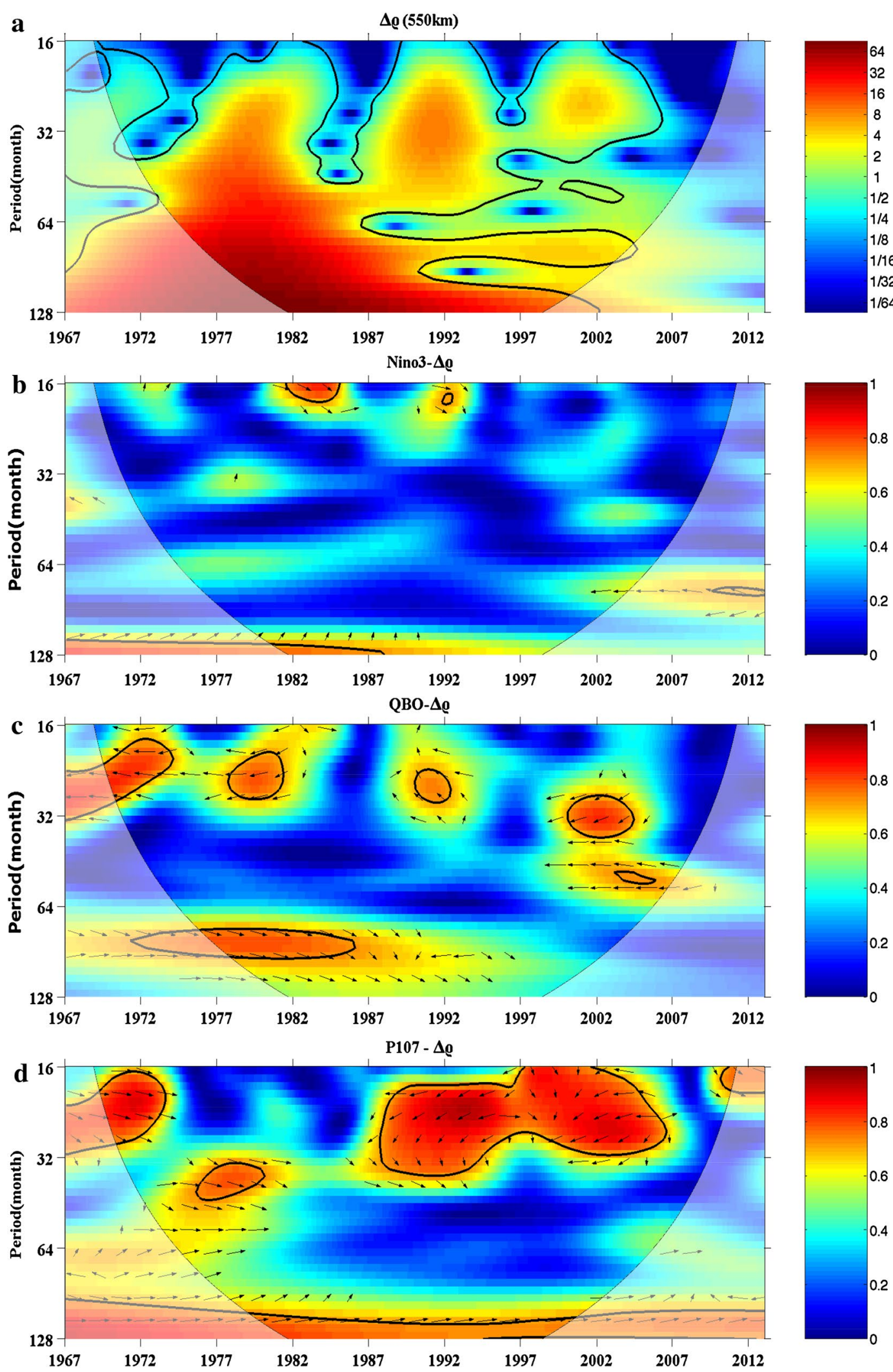

Fig. 6 a Wavelet power spectrum of the density residual at $550 \mathrm{~km}$ altitude. Wavelet coherence between Nino3 and the density residual (b), between QBO and the density residual (c), and between P10.7 index and the density residual (d). The thick contour encloses regions of greater than $95 \%$ significance level 
of the ENSO effect in the topside thermosphere. On the other hand, it has high coherence with the QBO around 28 months. But similar to the situation at $400 \mathrm{~km}$ altitude, this high coherence is significantly affected by the density and QBO's co-variation with solar flux as can be seen in Fig. 6d.

\section{Conclusions}

We examined the inter-annual variability of the thermospheric density residual and its potential link to ENSO and stratospheric QBO. The density residual is found to have high coherence with the QBO index at an average periodicity around 28 months at 250, 400 and $550 \mathrm{~km}$ altitude. However, their strong coherent variation with the solar flux makes difficult to tell whether there is a direct physical link between the density and the QBO. On the other hand, strong coherence between the density residual and the ENSO at an average period of $\sim 64$ months at 250 and $400 \mathrm{~km}$ altitude exhibits little contamination by co-variation with solar flux and hence indicates a more likely physical connection between the ENSO and the upper thermosphere.

Possible physical mechanisms which can cause such a teleconnection between the troposphere and thermosphere can be envisaged based on the following reasoning. ENSO is known to affect global climate and weather conditions by primarily altering the precipitation patterns in the tropics. Since absorption of solar heating by water vapor is the major source for tidal generation, changes in precipitation patterns will change the global distribution of water vapor and hence lead to changes in atmospheric tides. Indeed, there have been many studies showing an increase in the diurnal tides amplitude during ENSO period from both observational (Gurubaran et al. 2005; Lieberman et al. 2007) and model simulations (Lieberman et al. 2007; Pedatella and Liu 2012, 2013). It is known that both migrating and non-migrating diurnal tides can propagate upward to the thermosphere and cause perturbations in the thermospheric density (Liu et al. 2009, 2014; Yamazaki and Richmond 2013). Based on this knowledge, it is not a far stretch to consider that tidal changes may create a ENSO fingerprint in the thermospheric density. In addition, if ENSO also modifies planetary and gravity waves, these waves can also be potential carrier of ENSO effect to the thermosphere. Dedicated model simulations would be required to examine these possible mechanisms.

\section{Acknowledgements}

I thank Dr. John Emmert for providing the thermospheric data and helpful comments. This work is supported by JSPS KAKENHI Grants 15K05301, $15 \mathrm{H} 02135$ and $15 \mathrm{H} 03733$.

\section{Competing interests}

The author declares that he has no competing interests.

Received: 3 December 2015 Accepted: 28 April 2016

Published online: 10 May 2016

\section{References}

Baldwin MP (2001) The quasi-biennial oscillation. Rev Geophys 39:179-229 Emmert JT (2009) A long-term data set of globally averaged thermospheric total mass density. J Geophys Res 114:A06315. doi:10.1029/2009JA014102

Emmert JT, Lean JL, Picone JM (2010) Record-low thermospheric density during the 2008 solar minimum. Geophys Res Lett 37:L12102. doi:10.1029/2 010GL043671

Gurubaran S, Rajaram R, Nakamura T, Tsuda T (2005) Interannual variability of diurnal tide in the tropical mesopause region: a signature of the El NinoSouthern Oscillation (ENSO). Geophys Res Lett 32:L13805. doi:10.1029/2 005GL022928

Häusler K, Lühr H, Rentz S, Köhler W (2007) A statistical analysis of longitudinal dependences of upper thermospheric zonal winds at dip equator latitudes derived from CHAMP. J Atmos Solar Terr Phys 69:1419-1430

Kane RP (1995) Quasi-biennial oscillation in ionospheric parameters measured at Juliusruh (55 deg N, 13 deg E). J Atmos Terr Phys 57:415-419

Lieberman RS, Riggin DM, Ortland DA, Nesbitt SW, Vincent RA (2007) Variability of mesospheric diurnal tides and tropospheric diurnal heating during 1997-1998. J Geophys Res (Atmos) 112:D20110. doi:10.1029/200 7JD008578

Liu H, Lühr H, Henize V, Köhler W (2005) Global distribution of the thermospheric total mass density derived from CHAMP. J Geophys Res 110:A04301. doi:10.1029/2004JA010741

Liu L, Wan W, Ning B, Pirog OM, Kurkin VI (2006) Solar activity variations of the ionospheric peak electron density. J Geophys Res. doi:10.1029/200 6JA011598

Liu H, Lühr H, Watanabe S, Köhler W (2007) Contrasting behavior of the equatorial ionosphere and thermosphere in response to the Oct 28 (2003) solar flare. J Geophys Res 112:A07305. doi:10.1029/2007JA012313

Liu H, Yamamoto M, Lühr H (2009) Wave-4 pattern of the equatorial mass density anomaly — a thermospheric signature of tropical deep convection. Geophys Res Lett 36:L18104. doi:10.1029/2009GL039865

Liu H, Doornbos E, Yamamoto M, Tulasi Ram S (2011) Strong thermospheric cooling during the 2009 major stratosphere warming. Geophys Res Lett 38:L12102. doi:10.1029/2011GL047898

Liu H, Miyoshi Y, Miyahara S, Jin H, Fujiwara H, Shinagawa H (2014) Thermal and dynamical changes of the zonal mean state of the thermosphere during the 2009 SSW: GAIA simulations. J Geophys Res 119:6784-6791. doi:10.1002/2014JA020222

Lomb NR (1976) Least-squares frequency analysis of unequally spaced data. Astrophys Space Sci 39:447-462

Olsen N (1994) A 27-month periodicity in the low latitude geomagnetic field and its connection to the stratospheric QBO. Geophys Res Lett 21:1125-1128. doi:10.1029/94GL00180

Pedatella NM, Forbes JM (2009) Interannual variability in the longitudinal structure of the low-latitude ionosphere due to the El Niño-Southern Oscillation. J Geophys Res (Space Phys) 114:A12316. doi:10.1029/200 9JA014494

Pedatella NM, Liu H-L (2012) Tidal variability in the mesosphere and lower thermosphere due to the El Niño-Southern Oscillation. Geophys Res Lett 39:L19802. doi:10.1029/2012GL053383

Pedatella NM, Liu H-L (2013) Influence of the El Niño Southern Oscillation on the middle and upper atmosphere. J Geophys Res (Space Phys) 118:2744-2755. doi:10.1002/jgra.50286

Richards PG, Fennelly JA, Torr DG (1994) EUVAC: a solar EUV flux model for aeronomic calculations. J Geophys Res 99:8981-8992

Scargle JD (1982) Studies in astronomical time series analysis. II. Statistical aspects of spectral analysis of unevenly spaced data. Astron J 263:835-853

Trenberth KE, Caron JM, Stepaniak DP, Worley S (2002) Evolution of El NinoSouthern Oscillation and global atmospheric surface temperatures. J Geophys Res. doi:10.1029/2002JD000298 
Wang C, Picaut J (2004) Understanding ENSO physics - a review. In: Wang C, Xie S, Carton JA (eds) Earth's climate: the ocean-atmosphere interaction. Geophysics Monographical Series. AGU, Washington, DC, pp 21-48
Yamazaki Y, Richmond AD (2013) A theory of ionospheric response to upwardpropagating tides: electrodynamic effects and tidal mixing effects. J Geophys Res 118:5891-5905. doi:10.1002/jgra.50487
Submit your manuscript to a SpringerOpen ${ }^{\ominus}$ journal and benefit from:

- Convenient online submission

- Rigorous peer review

- Immediate publication on acceptance

- Open access: articles freely available online

- High visibility within the field

- Retaining the copyright to your article

Submit your next manuscript at springeropen.com 